\title{
REFORMS IN THE PENSION SYSTEMS OF BULGARIA AND POLAND - COMPARATIVE ANALYSIS
}

\author{
P. Enev* \\ Trakia University, Stara Zagora, Bulgaria
}

\begin{abstract}
The socio-economic changes occurred after 1989, face the problems of the pension systems of Bulgaria and Poland. The challenges faced by the social security systems called for a completely new reforming philosophy. A multi-pillar model of social protection has been introduced with the specifics in both countries.

The article's main goal is to follow the reforms implemented in the social security systems of Bulgaria and Poland by examining individual solutions in the field of social security policy, pointing out current challenges and trends in the two pension systems.

To achieve this goal the following tasks are completed:

- Analysis of the social security systems starting from the beginning of the $90 \mathrm{~s}$ and of the undertaken measures and steps concerning the reform conduct;

- Analysis of the reform's results in relation to the requirements for adequacy and financial sustainability of the new pensions;

- Analysis of current challenges facing the pension systems of Bulgaria and Poland;

The methods utilized during the study are the system approach, statistical evaluations, analysis and synthesis, comparison methods and others.
\end{abstract}

Key words: social security, sustainability, adequacy.

\section{INTRODUCTION}

Bulgaria and Poland have faced new economic and demographic challenges since the 1989 political and economic changes. The social security systems of both countries could not respond to the new realities and need to be reformed. Reforms in the pension systems of both countries started in the late 1990s and the goals set were to ensure financial sustainability and adequacy of long-term retirement benefits.

The article's main goal is to follow the reforms implemented in the social security systems of Bulgaria and Poland by examining individual solutions in the field of social security policy, pointing out current challenges and trends in the two pension systems.

\section{MATERIAL AND METHODS}

To achieve this goal the following tasks are completed: analysis of the social security systems starting from the beginning of the 90s

\footnotetext{
*Correspondence to: Plamen Enev, Trakia

University, Stara Zagora, Bulgaria, enev74@abv.bg
}

and of the undertaken measures and steps concerning the reform conduct; analysis of the reform's results in relation to the requirements for adequacy and financial sustainability of the new pensions; analysis of current challenges facing the pension systems of Bulgaria and Poland;

The methods utilized during the study are the system approach, statistical evaluations, analysis and synthesis, comparison methods and others.

\section{DISCUSION AND RESULTS}

The social security systems of Bulgaria and Poland cover the main insurance risks (old age, incapacity, illness, death of the head of the family, occupational diseases and accidents at work, death) and the functioning of the systems is based on the implementation of the respective legislation acts, regulating the problems in the social security sphere. The implementation of the provisions in this area in both countries is entrusted to insurance institutions, operating at central and regional levels.

Poland is one of the first countries to reform their pension systems. The reasons for that are 
identical to those in Bulgaria - inefficiency of the old system, negative demographic trends, increasing deficit in social insurance funds. A three-pillar pension model was introduced in both countries, each model having its specific characteristics. In 1999 Poland introduced the three-pillar pension model, replacing the old PAYG (pay-as-you-go) pension system and changing the pension formula - from defined contribution plans to notion defined contribution schemes (NDC), which created a stronger link between the contributions paid and the pensions received. The model involved the following three components:

- $\mathrm{I}^{\text {st }}$ pillar (mandatory) - representing a PAYG system, within which a State Social Security Fund (FUS), administered by the Social Insurance Institute (ZUS) (1) was established. It was built on mandatory contributions and individual-funded accounts that yield a return equal to the wage growth and long-term GDP.

Revenues received by ZUS come mainly from social security contributions, state budget funds (plus the funds to compensate for the portion of the total contribution contributed to the second pillar) plus the funds from the newly created Demographic Reserve Fund (FRD).

The Demographic Reserve Fund has the status of a special fund and was established to ensure the sustainability of the state pension system by supporting the payment of old-age pensions.(2) Its revenues are formed with a part of the pension contributions, proceeds from the privatization of state-owned enterprises and return on investments. In order to achieve a higher return the Fund invests in various financial instruments - bonds, stocks, treasury bills and bank deposits. The Silver Fund in Bulgaria however is financed in an entirely different way - its revenues are mainly formed from budget surpluses and the fund itself is a part of the country's fiscal reserve. It is also characterized by a low investment activity with zero profitability having been achieved since 2012 .

- II ${ }^{\text {nd }}$ pillar (mandatory) - operates on a capital-funded principle with Open Pension Funds (OFE), managed by private pension companies. Funding is provided by mandatory contributions to the individual accounts of the insured individuals. Contributions are accumulated and invested throughout the length of service of the insured person and the amount of the second-pillar pension depends on the accumulated amount and the retirement age. Open Pension Funds are subject to state oversight by the Financial Supervision Committee (KNF).
In Bulgaria and in Poland the basic pension is formed by the mandatory first and second pillars.

- III $^{\text {rd }}$ pillar (voluntary) - including Professional Pension Schemes (PPE) and two types of individual pension accounts (IKE, IKZE), operates on a capital-funded principle. Like the second pillar revenues the third pillar funds are administered by private institutions. All working people, including those insured pursuant to the provisions of the old system, can make savings in the third-pillar pension scheme.

The organization and functioning of the Professional pension schemes is similar to these in Bulgaria. What is specific here is that, unlike Bulgaria, where these schemes are included in the second pillar, have an obligatory nature and bear the early retirement burden, those in Poland are voluntary and depend mainly on the will of the employer who pays the social security contributions.

People born before 01.01.1948 are insured entirely by the old PAYG system. Those born between 01.01.1948 and 31.12.1968 have the option to be fully insured in the new NDC system (first pillar) or to participate in both insurance pillars. For those born after 31.12.1968 insurance in both the first and second pension pillar is compulsory.

Under the new system anyone who has reached the statutory retirement age (60 for women and 65 for men), can retire irrespective of the length of service and the amount of the pension depends mainly on the capital accumulated in the pension accounts.

In 2012 steps were taken to increase the retirement age to 67 and to make it the same for men and women, starting in 2013. The law provides for the retirement age to get increased every four months with one month. Thus the retirement age of 67 shall be reached by women in 2040 and in 2020 for men. The insurance contribution is set at $19,52 \%$, equally shared by worker and the employer in a 50:50 ratio. $12,22 \%$ of the total amount of the contribution $(19,52 \%)$ goes to the first pension pillar, while $7,3 \%$ are contributed to the second pillar. It should be noted that the amount of the pension contribution has remained unchanged since the beginning of the reform (unlike Bulgaria for example), the changes over the years having been seen in the different ratios between the first and second pillars. A comparison of the pension models in Bulgaria and Poland is presented in Table 1. 
Table 1. Organization of the three-pillar pension model in Poland and Bulgaria

\begin{tabular}{|c|c|c|c|c|}
\hline & \multicolumn{2}{|l|}{ POLAND } & \multicolumn{2}{|l|}{ BULGARIA } \\
\hline Pillar & Pension Scheme & Obligation & Pension Scheme & Obligation \\
\hline $\begin{array}{l}1^{\text {st }} \\
\text { pillar }\end{array}$ & $\begin{array}{l}\text { PAYG system with notion } \\
\text { defined contributions (NDC) }\end{array}$ & mandatory & PAYG system & mandatory \\
\hline \multirow[t]{2}{*}{$\begin{array}{l}2^{\text {nd }} \\
\text { pillar }\end{array}$} & $\begin{array}{l}\text { Capital-funded pension } \\
\text { scheme(FDC) with privately } \\
\text { managed open pension funds } \\
(\mathrm{OFE})\end{array}$ & mandatory & $\begin{array}{l}\text { Capital-funded pension } \\
\text { scheme with privately } \\
\text { managed pension funds } \\
\text { (UPF) }\end{array}$ & mandatory \\
\hline & & & \begin{tabular}{|l|}
$\begin{array}{l}\text { Professional pension } \\
\text { schemes }\end{array}$ \\
\end{tabular} & mandatory \\
\hline \multirow{2}{*}{$\begin{array}{l}3^{\text {rd }} \\
\text { pillar }\end{array}$} & Professional pension schemes & voluntary & Voluntary Pension funds & voluntary \\
\hline & Individual pension accounts & voluntary & $\begin{array}{l}\text { Voluntary pension funds } \\
\text { under occupational schemes }\end{array}$ & voluntary \\
\hline
\end{tabular}

Source: NSSI, ZUS

Diverting a portion of the contribution $(7,3 \%)$ to the second pension pillar leads to a reduction of the funds needed by ZUS for the payment of the current pensions. The state is therefore refinancing the ZUS budget with the amount sent to the Open pension finds (OFE).

Open pension funds, on their part, invest the collected funds in shares and other securities, including government bonds. The government bonds bought by the open pension funds are subsequently repurchased by the state, together with the interests due thereon.

The system caused an increase of public debt and state budget deficit respectively, with the total state debt reaching the critical 53,3\% in 2010. In this situation the legislator decided to reduce the amount of the contribution transferred to OFE and leave part of it in a special sub-account in ZUS. According to the government it was necessary to divert contributions to ZUS in order to reduce Poland's budget deficit which was approximately $8 \%$ of the Gross domestic product (GDP) in 2010 and to maintain the national debt below the threshold of $55 \%$ of the GDP, set by the constitution of Poland.(3) In 2011 the portion of the second pillar contributions was reduced from $7,3 \%$ to $2,3 \%$, while the remaining $5 \%$ were redirected to the state pension system and the newly created subaccounts.

It was stipulated that the newly established sub-accounts shall be indexed according to the average value of the GDP nominal growth over the previous 5 years (excluding any decline in GDP).

The major changes in the Polish social security system, however, occurred at the end of 2013 and affected mainly the second pillar of the existing pension model.

As of 1 February 2014 participation in the second pension pillar became voluntary for all people born after 31.12.1968 while up to that moment it had been mandatory. All new participants in the labour market had to explicitly state their desire to participate in OFE. The participants of the previously obligatory capital scheme were allowed to give it up and to transfer the funds from their individual accounts to state social security funds against recovery of their full state pension rights. Current OFR participants were allowed, as of 1 April 2014, to state in writing whether they want to continue their participation in the second pillar. Those, who fail to exercise that option within that deadline will discontinue their participation and will continue to be insured in the public social security system. Their private individual account funds shall automatically be transferred to the first pillar. The law provides for the participants in the second pillar to give it up in 2016 and that opportunity will be available in the future every four years.

All government bonds are transferred from the second pillar to the first one and the investment opportunities for the OFEs are changed. The goal is to reduce the amount of the steadily rising government debt.

Data show that from $56 \%$ in 2013 public debt declined to $50,5 \%$ of the GDP in 2014. (4)

In addition private funds are forbidden to invest in state-owned Polish bonds although they can invest in government bonds of other EU countries. Similar reforms of a systemic nature in the three-pillar model are also under way in Bulgaria. All people born after 31.12.1959 are given the possibility to choose between two alternatives - to be compulsorily insured for an additional pension in an UPF or only for a life pension in the State social security scheme. It is a one-off option and the insured individuals have to make that choice 
not later than 5 years before the age under Article 68, Para 1 of the Social Security Code. The redirection of funds from a Professional pension fund to the Public pension system can be made only once. Upon that change the funds accumulated in the individually-funded account of the insured individual shall be transferred to the State Fund for Guaranteeing the Stability of the State Pension System.

Reforms in the parameters of the required length of service and retirement age are continuing, the aim being their gradual increase.

The reform in the Bulgarian and Polish pension systems having begun in the late $20^{\text {th }}$ century aims at overcoming the problems inherited from the old system and meeting the new challenges - economic and demographic, which, ultimately, shall lead to financial stability and adequate retirement benefits.

The first element determining financial sustainability is the amount of the insurance contribution. It has already been pointed that the total amount of the contribution has remained unchanged since the beginning of the reform thus leading not to self-financing of the system but to an increase of its deficit. In Bulgaria, although the insurance contribution is fixed at a higher level (32\%) a tendency for the reduction of the contribution rates has begun since 2000 and by 2011 the first-pillar contribution reached $12,8 \%$ which is commeasurable with the first-pillar contribution in the Polish pension system $(12,22 \%)$. Deficits are being generated in both countries and they are paid mainly through fund transfers from the state budget. Chart 1 presents deficit data over the last five years in the Pension Funds in Bulgaria and Poland.

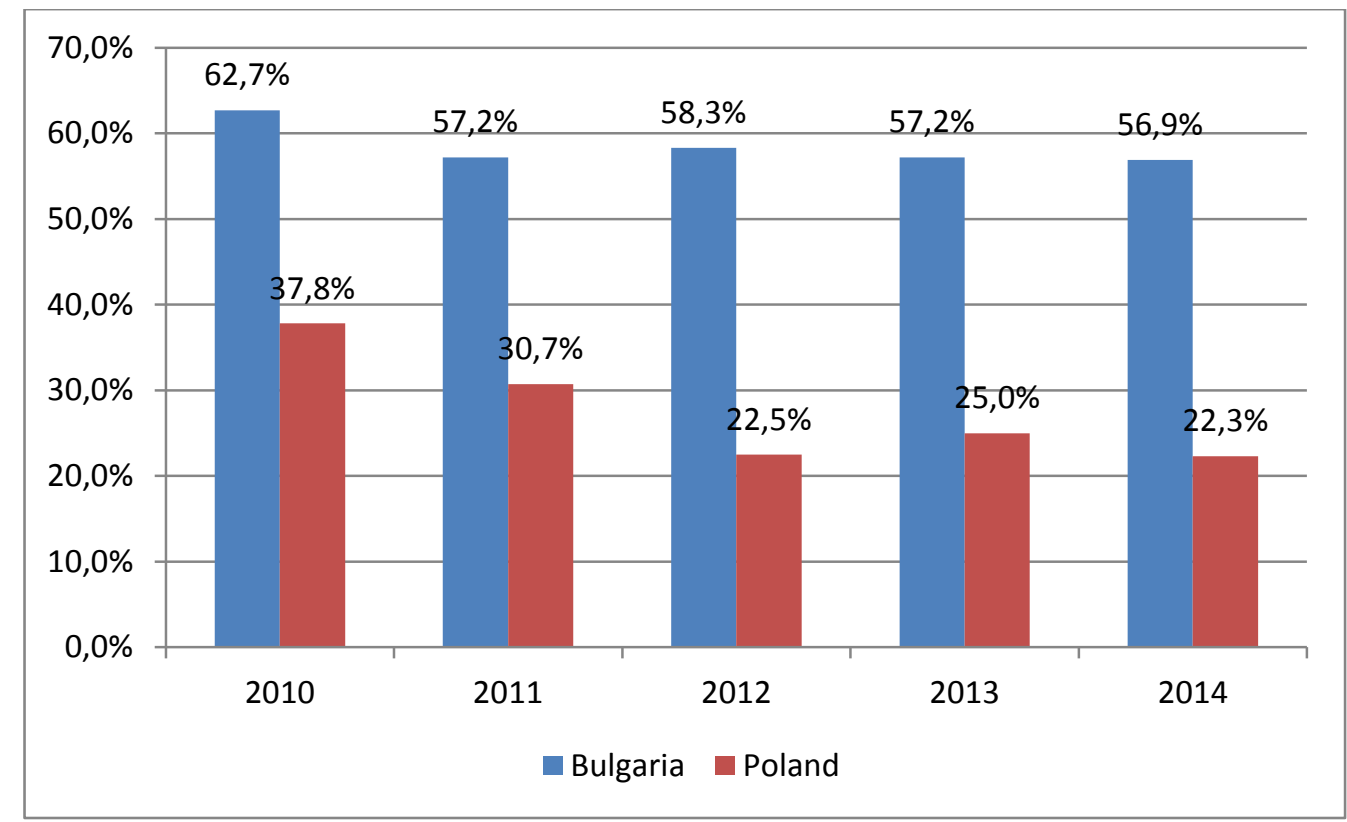

Source: NSSI, ZUS

Chart 1. Pension Fund deficit for the period 2010-2014

In 2010, the year preceding the serious changes in the Polish social security system, the deficit accumulated in the Pensions Fund was almost $38 \%$. That called for the start of reforms to reduce the deficit and, as of 2014, it was reduced to $22,3 \%$. At the same time the total deficit in ZUS in 2010 was $40,5 \%$, while at the end of 2014 it decreased with 12 percentage points, amounting to $28,5 \%$. Reforms in the Polish social security system resulted in decreasing the ZUS deficit and the public debt as well, which in 2013 reached $56 \%$ of the GDP and by the end of 2014 was reduced to $50,5 \%$. However these are shortterm results having been achieved through radical reforms and transfer of funds from the OFEs and it is too early to believe that a long- term financial sustainability has been achieved.

As can be seen from the chart as of 2014 the state budget funding was in the amount of $22,3 \%$ in Poland, the percentage being much higher in Bulgaria $-56,9 \%$. The reasons for the accumulation of deficit and the serious difference in both countries can be found both in terms of social security contributions (revenue to the system) and in terms of costs (early retirement, disability pensions, pension indexation). For example, the number of disability pensions in Poland for the period 2000-2014 decreased from 2,5 million in 2000 to 993500 in 2014, which is a decrease by a factor of 2,5. (5) The relative percentage of disability pensions in Poland decreased from 
about $34 \%$ in 2000 to $13,7 \%$ of all pensions by the end of 2014. The relative share of disability pensions in Bulgaria for the same period increased from about $9 \%$ in 2000 to $20,3 \%$ of all pensions by the end of 2014 .

The other element, which is directly relevant to the stability of the pension system, is the demographic factor. Chart 2 shows the values of the dependency ratio for the period 2000 2015, which give an idea of population ageing.

The chart shows a clear trend towards worsening of demographic picture which is also characteristic of the EU as a whole. Both countries follow the general negative trend in EU regarding population ageing. (6) The difference is in the pace and scale of ageing. The data show that for the analyzed period the pace of ageing in Poland is within 4,4 percentage points, while in Bulgaria it is 6,4 percentage points in an obviously worse population age structure. With equal other conditions this means more pensioners and more expenditure for retirement benefits in the future respectively. This, in turn, leads to an alarming conclusion about expected financial instability of pensions systems.

Besides achieving financial sustainability pension reforms also aim at improving pension adequacy. The results of the reform may be assessed through the values of the income replacement ratio (Chart 3).

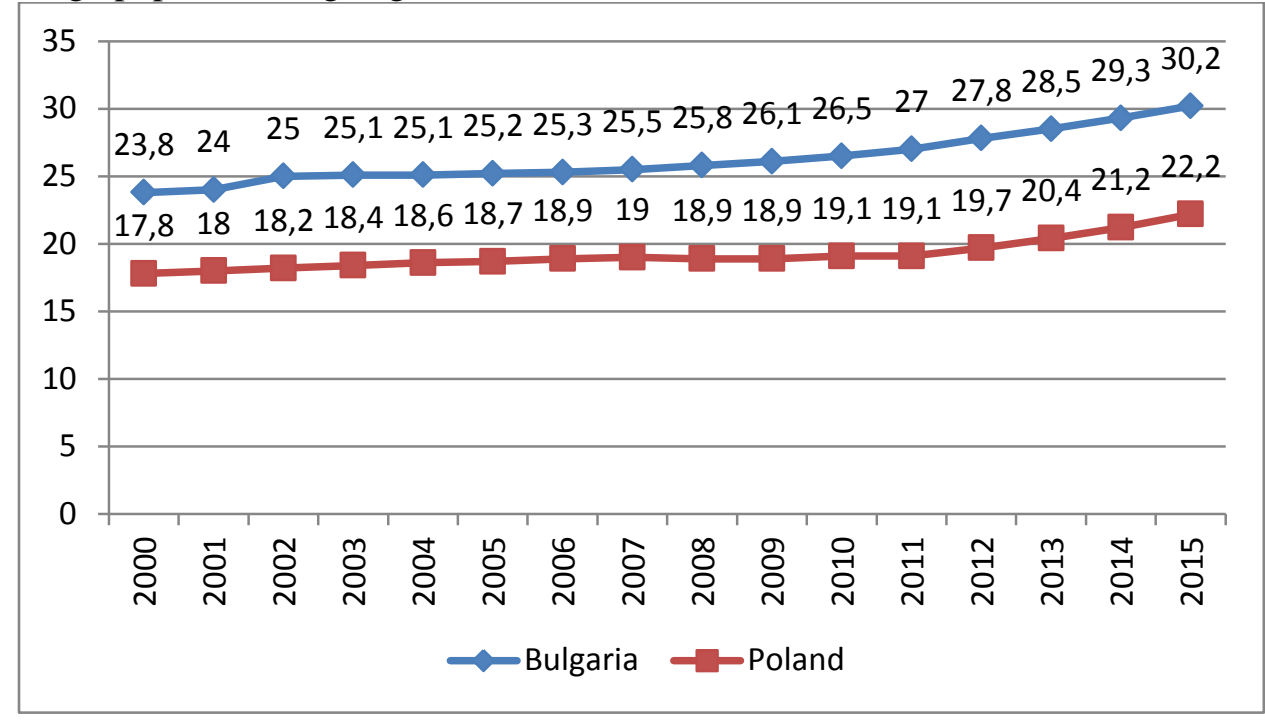

Source: Eurostat

Chart 2. Age dependency ratio

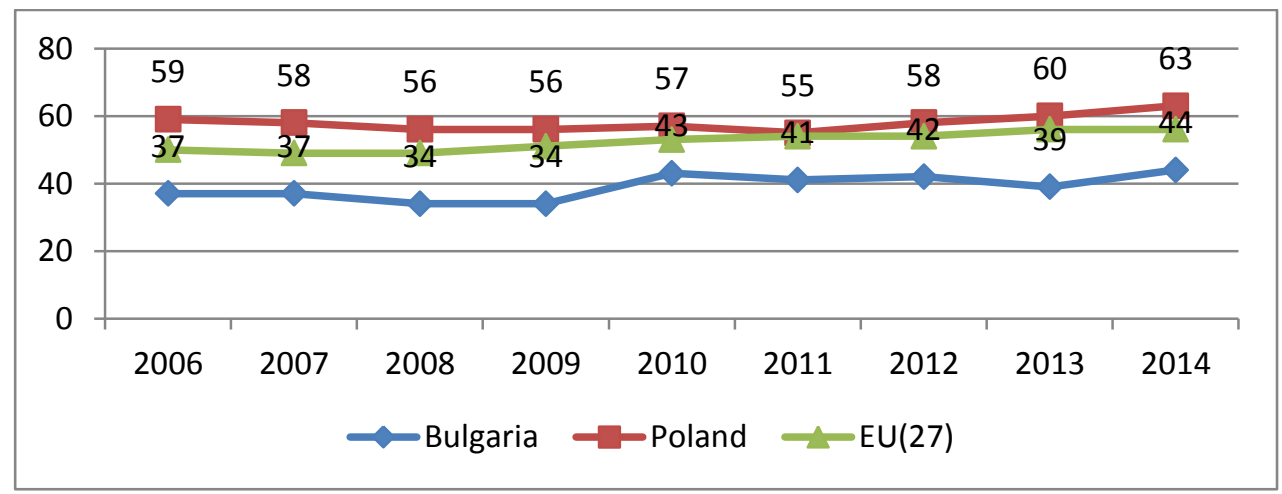

Source: Eurostat

Chart 3. Income replacement ratio

Data show that the level of income replacement in Bulgaria is significantly lower than that in Poland and the average EU income replacement rate. While comparing the levels of income it is also necessary to stress that there are notable differences in the amount of pensions in both countries. For example, in 2014, the minimum pension in Poland was in the amount of PLN 880, 45 (about EUR 212) (7) or $52,4 \%$ of the minimum wage. In 2014 in Bulgaria the minimum pension was set to BGN 154,50 (EUR 79), which is less by a factor of 2,6 than the minimum pension in Poland.

Cost policy, characterizing the generosity of the pension system to pensioners can be assessed through the GDP share redistributed through it. Chart 4 shows the valued of that indicator for Bulgaria and Poland. 


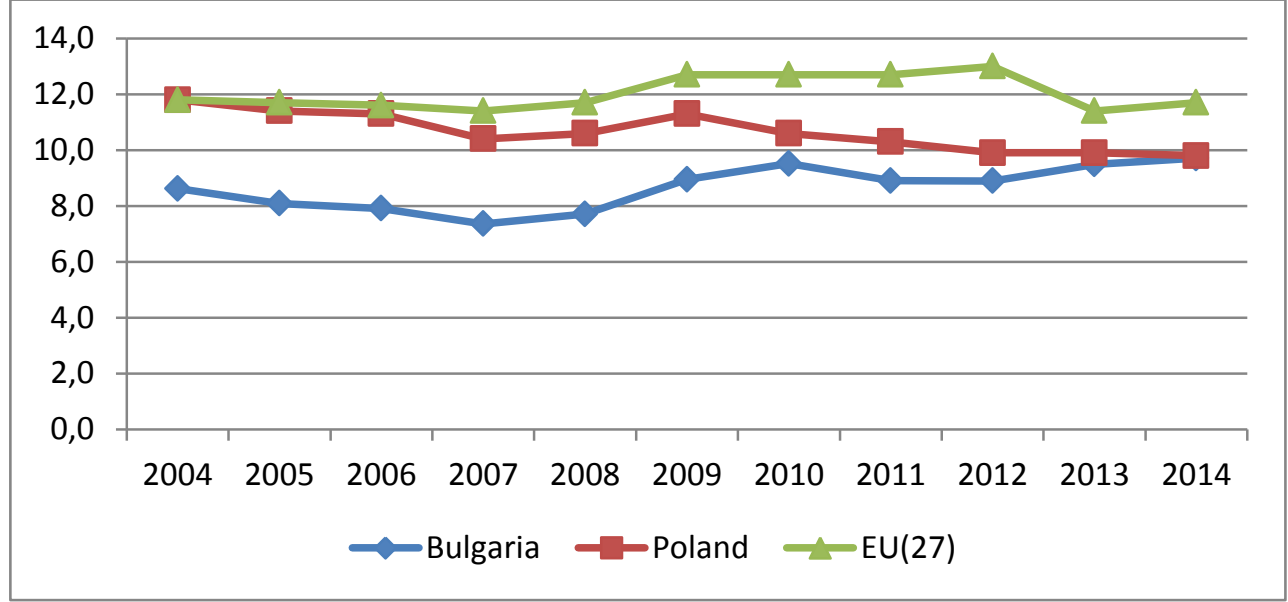

Source: Eurostat, NSSI

Chart 4. Pension expenditure as a percentage of the GDP

It is clear from the chart that for the analyzed period the values of that indicator in Bulgaria are far behind the same indicator in Poland and the EU average indicator value. Until 2010 the dynamics of pension expenditure in Bulgaria and Poland followed closely the dynamics of the EU indicator, but the trend has been broken since 2010 .

From a financial point of view it can be concluded, for both Bulgaria and Poland, that despite the short-term budget relief that the radical 2013-2014 reform will bring, this will not improve the long-term sustainability of the pension system and public finance as the short-term positive effect of the higher amount of social security contributions and the redirection of individual account funds to the first pension pillar will be compensated by higher future pension payments from the public pension insurance pillar.

\section{CONCLUSIONS}

Looking back at the reforms that have been carried out and having in mind the results achieved it can be concluded that the reform of the pension systems is necessary and without an alternative. While individual decisions and policies can be seriously criticized the conclusion is that a bad reform of the old pension system is better than none. The indicators for financial sustainability and adequacy of the pension systems in Bulgaria and Poland that have been presented and analyzed confirm the correctness of the reforms although there is still much to be desired regarding the stability factor and the adequacy of pension payments. The frequent legislative changes of the social security system are a sign of its strong political dependence and they undoubtedly erode trust in the pension system and are not beneficial to society as a whole.

The future risks for the pension systems of both countries are as follows:

-Economic - negative growth caused by domestic and global crises, decline in employment and income, high share of informal economy, etc.;

-Demographic - negative natural population growth and a continuous trend of population ageing and deterioration of the population age structure, etc.;

-Political - decisions that lead to deficits and instability of pension systemл

\section{REFERENCES}

1. Social Insurance Institute (ZUS)

2. Social insurance in Poland, ZUS, 2013

3. Social security administration(USA)

4. Eurostat and Poland's Central Statistics Office

5. According to ZUS and my own calculations

6. Ageing Report 2015

7. Social insurance in Poland, ZUS, 2015 